\title{
PERCEPÇÕES DE JOVENS EM CONFLITO COM A LEI PRIVADOS DE LIBERDADE: EDUCAÇÃO E SOCIALIZAÇÃO
}

\author{
PERCEPTIONS OF YOUNG PEOPLE IN CONFLICT WITH THE PRIVATE LAW OF \\ FREEDOM: EDUCATION AND SOCIALIZATION
}

\section{PERCEPCIONES DE JÓVENES EN CONFLICTO CON LA LEY Y PRIVADOS DE LIBERTAD: EDUCACIÓN Y SOCIALIZACIÓN}

\section{Lia Machado Fiuza Fialho ${ }^{1}$; José Gerardo Vasconcelos ${ }^{2}$}

\begin{abstract}
RESUMO
A pesquisa objetivou compreender as percepções juvenis acerca do significado da experiência socioeducativa de internação, medida privativa de liberdade que se propõe a ser educativa e socializadora. Com a metodologia da história oral biográfica, coletaram-se sete entrevistas livres como fontes primárias. Os resultados apontaram característica acerca do perfil dos jovens - defasagem escolar, ingresso precoce no mercado de trabalho, baixa renda, desagregação familiar e reincidência infracional - e exprimiram cinco categorias que problematizam a experiência da internação - violência sofrida, identidade infratora, perspectivas e planos dos jovens, código de ética e significado da internação. A discussão, realizada mediante a análise de conteúdo, constatou percepções negativas referentes à socioeducação e educação na internação associada à perda de tempo e prevalência do caráter punitivo em detrimento do educativo, já que o disciplinamento coercitivo promovia clima pouco amistoso sob a tônica da violência e a educação era negligenciada e relegada a plano inferior de importância.
\end{abstract}

PALAVRAS-CHAVE: Jovem. Educação. Internação. Socioeducação. Ressocialização.

\begin{abstract}
This research aimed to understand the juvenile perceptions about the meaning of the socioeducative experience of internment, a measure deprived of freedom, which proposes to be educational and socializing. With the biographical oral history methodology, seven free interviews were collected as primary sources. The results showed some characteristics about those young people's profile (school lag, early admission to the labor market, low income, family breakdown and infraction) and they expressed five categories that problematize the experience of internment (violence, a delinquent identity, young people's perspectives and plans, a code of ethics and a meaning to internment). The discussion, carried out through the analysis of contents, found negative perceptions regarding the socioeducation and education in the internment associated with the loss of time and the prevalence of the punitive character to the detriment of the educational one, since the coercive discipline promoted an unfriendly climate under violence and education was neglected and relegated to lower plane of importance.
\end{abstract}

KEYWORDS: Young person. Education. Internment. Socioeducation. Ressalization.

\footnotetext{
${ }^{1}$ Doutorado em Educação - Universidade Federal do Ceará (UFC) - Benfica, Fortaleza, CE - Brasil . Professora Doutora - Universidade Federal do Ceará (UFC) - Benfica, Fortaleza, CE - Brasil. E-mail: lia fialho@yahoo.com.br ${ }^{2}$ Doutorado em Sociologia - Universidade Federal do Ceará (UFC) - Benfica, Fortaleza, CE - Brasil. Professor Titular - Universidade Federal do Ceará (UFC) - Benfica, Fortaleza, CE - Brasil. E-mail: gerardovasconcelos1964@gmail.com
}

Submetido em: 20/12/2017 - Aceito em: 23/07/2018

(C) ETD- Educação Temática Digital Campinas, SP $\quad$ v.21 n.1 $\quad$ p.126-144 jan./mar. 2019 


\section{RESUMEN}

La investigación objetivó comprender las percepciones juveniles acerca del significado de la experiencia socioeducativa de la internación, una medida privativa de libertad que se propone a ser educativa y socializadora. Con la metodología de la historia oral biográfica, se recogieron siete entrevistas libres como fuentes primarias. Los resultados apuntaron algunas características sobre el perfil de los jóvenes - desfase escolar, ingreso precoz en el mercado de trabajo, bajos ingresos, desagregación familiar y reincidencia en la infracciones - y expresaron cinco categorías que problematizan la experiencia de la internación - violencia, identidad infractora, perspectivas y planes de los jóvenes, código de ética y significado de la internación-. La discusión, realizada mediante el análisis de contenido, constató percepciones negativas referentes a la socioeducación y a la educación en la internación asociadas a la pérdida de tiempo y a la prevalencia del carácter punitivo en detrimento del educativo, ya que la disciplina coercitiva promovía un clima poco amistoso bajo la tónica de la violencia y la educación era descuidada y relegada a un plan inferior de importancia.

PALABRAS CLAVE: Joven. Educación. Internación. Socioeducación. Resocialización.

\section{INTRODUÇÃO}

O estudo sob relato objetivou compreenderas percepções de jovens em conflito com a lei que cumpriam medida socioeducativa de internação ${ }^{3}$ acerca do significado da experiência de privação de liberdade, propondo-se a fomentar educação e socialização. Delineou-se, pois, uma problemática central: como a experiência de internação interfere na educação e na vida dos jovens em conflito com a lei? A resposta à inquietação em tela foi desvelada por uma investigação realizada no ano de 2015 que refletiu sobre o sentido atribuído à educação e à ressocialização ${ }^{4}$ pelos jovens institucionalizados por intermédio da socioeducação.

No tocante à prática de atos infracionais ${ }^{5}$ por jovens, é notória a relevância dessa temática em decorrência do aumento da visibilidade que gradativamente adquire não apenas dos juristas, mas também da sociedade como um todo (ZANELLA; LARA, 2015). A contravenção na juventude é expressa como um problema crescente no Brasil e em diversos países - em especial, El Salvador, Ilhas Virgens (EUA), Venezuela, Colômbia e Guatemala que acarreta prejuízos no âmbito econômico, político e social; inclusive, observa-se uma tendência mundial no aumento da violência exercida na juventude (ASSIS; SOUSA, 1999). Pode-se constatar "[...] uma epidemia de homicídios no Brasil com taxa de assassinatos de 56 mil mortos por ano", destes 30 mil são jovens entre 15 e 29 anos de idade (ALMEIDA,

\footnotetext{
${ }^{3}$ A medida socioeducativa de internação é a mais severa dentre as seis existentes - advertência, obrigação de reparar o dano, prestação de serviço à comunidade, liberdade assistida, regime de semiliberdade e internação -, a qual consiste na privação de liberdade e no controle de ir e vir do adolescente, vinculando-o a um estabelecimento especializado.

${ }^{4}$ Entende por ressocialização o ato de reintegrar novamente ao convívio social uma pessoa que se desviou por meio de condutas reprováveis pela sociedade. Já a socialização envolve aprendizagem ou educação, pois implica a adaptação a certos padrões culturais existentes na sociedade, capacidade para viver em sociedade harmonicamente com civilidade.

${ }^{5}$ Segundo o artigo 103 do Estatuto da Criança e do Adolescente (ECA), considera-se ato infracional a conduta que para o maior é descrita como crime ou contravenção penal. $\mathrm{O}$ ato contrário à lei praticado por jovens de 12 a 18 anos incompletos é considerado ato infracional.
}

(C) ETD- Educação Temática Digital Campinas, SP v.21 n.1 $\quad$ p.126-144 jan./mar. 2019 
2017, p. 567). Salienta-se que, no caso do Ceará, a necessidade de investimento em estudos nessa área é ainda maior, já que esse estado ocupa o primeiro lugar em número de mortes por assassinatos na juventude e o envolvimento de jovens com atos infracionais prejudica a educação formal (FIALHO, 2015b; WAISELFISZ, 2016).

Alguns pesquisadores já desenvolveram estudos com vistas a analisar a educação e ressocialização do jovem em conflito com a lei, estudando a estrutura familiar, as condições econômicas, a escolarização, os profissionais envolvidos, as atividades profissionais, o processo jurídico, dentre outros (BRANCO; WAGNER, 2009; EDUARDO; EGRY, 2010; OLIVEIRA; ASSIS, 1999; PRIULI; MORAES, 2007).

Este estudo, no entanto, não se limita a identificar características comuns ou buscar as causas da prática de atos infracionais, tampouco a ensejar luz à visão dos formuladores das políticas públicas nesse campo; na contramão, busca compreender as percepções de jovens em conflito com a lei, ao conceder visibilidade à voz de jovens muitas vezes excluídos por cumprirem medida socioeducativa de internação. Ouvir os sujeitos "anônimos" e compreender o significado dessa experiência na interface com sua educação e socialização se torna relevante por possibilitar outras versões históricas, mais fidedignas, por serem elaboradas justamente pelos que vivenciam na prática as ações educativas e socializadoras (MESQUITA; FONSECA, 2006).

Importa permitir àqueles jovens que se configuram no cerne do processo educativo e socializador a possibilidade de opinar acerca das ações direcionadas a eles, bem como sobre os motivos que os conduziram ao ato infracional, o significado da internação em suas trajetórias de vida, a relevância aferida à educação e finalmente suas perspectivas e sonhos. Afinal, já não se concebem mais projetos e ações de intervenção para a juventude sem que esta ocupe o centro do processo decisório de maneira autônoma, como protagonista, ao invés de permanecer excluída e invisibilizada na sociedade (BRANCO; WAGNER, 2009).

Importa esclarecer que, segundo o Estatuto da Criança e do Adolescente (ECA), Lei no 8.069, de 13 de julho de 1990 (BRASIL, 1990), que dispõe sobre a proteção integral à criança e ao adolescente, vigente nos dias atuais, considera-se criança a pessoa com até 12 anos de idade incompletos e adolescentes aqueles de 12 a 18 anos de idade. Tais construtos - criança e adolescente - foram fruto de elaborações históricas, corriqueiramente utilizadas nas normas legais e definidas levando em consideração prioritariamente a idade da pessoa. Percebe-se, entretanto, que o construto adolescência carrega consigo um arcabouço de significados universalizados que colaboram para instaurar uma ideia universal e anistórica do desenvolvimento humano, homogeneizando indivíduos distintos, principalmente pela característica etária, ao invisibilizar o dinamismo social e a pluralidade dos grupos juvenis (CANETTI; MAHEIRIE, 2010). Logo, optou-se, nesta pesquisa, por trabalhar com o conceito de juventudes, pois se acredita que essa categoria é conceitualmente mais imprecisa, na

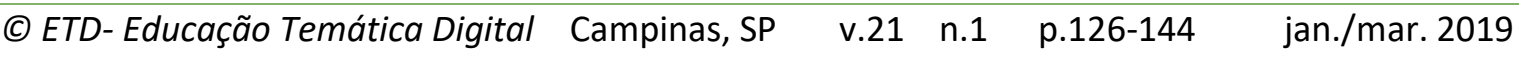


medida em que abarca contextos e situações de vida variados e com poucos elementos em comum (SPOSITO, 2000).

O aumento de infrações envolvendo jovens com idades inferiores a 18 anos, a aparente precariedade dos recursos financeiros e de pessoal qualificado para efetivar políticas centradas em reverter a situação de violência juvenil, a baixa qualidade da educação pública formal, a superlotação de instituições destinadas ao atendimento do público jovem em conflito com a lei no Brasil, as altas taxas de reincidência infracional, o questionável caráter educativo e ressocializador dos centros de atendimento aos jovens internos, dentre outros aspectos que perpassam a problemática da violência juvenil, põem em xeque a funcionalidade do sistema socioeducativo que atende a esse público e suscita reflexões acerca da maneira como a educação e a socialização são desenvolvidas nas instituições de privação de liberdade (FIALHO, 2015a). Ante esse contexto, defende-se o argumento de que o aprisionamento repressivo nos moldes socioeducativos desenvolvidos no Centro Educacional Patativa do Assaré (CEPA) impossibilita o alcance da autonomia e, por conseguinte, a educação e a recuperação social dos jovens em conflito com a lei privados de liberdade.

\section{PERCURSO METODOLÓGICO}

Ancorado no campo teórico da história presente, o estudo ensejou a "história dos vencidos", ao tempo que permitiu configurar o universo histórico-social e, por conseguinte, a localização da vida dos jovens em conflito com a lei no cenário de suas atuações educacionais e socioculturais; grupo silenciado pelo parco ensejo à visibilidade de suas narrativas (FERREIRA; AMADO, 2006; FIALHO, 2015a; MONTENEGRO, 2007; THOMPSON, 1992). Haja vista a necessidade e a possibilidade de se ouvir os sujeitos envolvidos em seus decursos de infrações, educação e ressocialização, captar suas experiências e perceber as especificidades que a contravenção implica na vida dos jovens, optou-se pela história oral como principal técnica de coleta de dados (MEIHY; RIBEIRO, 2011).

Após autorização da Secretaria de Trabalho e Desenvolvimento Social (STDS) da cidade de Fortaleza, Ceará (CE), que mantém formalmente a guarda e a responsabilidade legal dos jovens autores de atos infracionais privados de liberdade, concedida mediante análise e aprovação do projeto de pesquisa, foi fornecido o consecutivo consentimento junto ao CEPA para acesso irrestrito à Instituição, como preconizam os critérios éticos. 0 CEPA é a única instituição privativa de liberdade para menores de idade na faixa etária de 17 anos do sexo masculino localizada na cidade de Fortaleza-CE.

Como o CEPA possuía sete blocos de dormitórios e os jovens eram inseridos nestes de acordo com a infração cometida, as atividades desenvolvidas na Instituição ou a cidade de procedência, escolheu-se convidar sete jovens do universo de aproximadamente 200 internos, sendo um de cada bloco, no intuito de abarcar uma compreensão qualitativa ampla, já que a rotina dos internos variava conforme o local de alojamento: jovens vindos

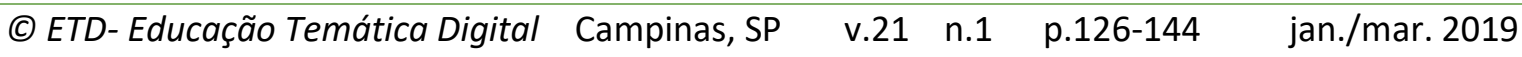


do interior do estado; que trabalhavam na fábrica anexa ao CEPA; que haviam cometido atos infracionais (estupradores, homicidas de mulheres e crianças) não aceitos pelos demais internos; que haviam perturbado a ordem da casa e estavam em isolamento na tranca; que haviam cometido apenas roubo; que haviam praticado infrações hediondas. Todos os participantes assinaram o Termo de Consentimento Livre e Esclarecido, que assegurava sigilo e confidencialidade dos dados, bem como participação voluntária, que poderia ser interrompida em qualquer etapa, sem nenhum prejuízo ou punição. Os jovens foram denominados ficticiamente de Felipe, Gabriel, João, José, Mateus, Paulo e Pedro, visando à preservação da identidade.

As entrevistas livres individuais em história oral, previamente pensadas e cuidadosamente agendadas, possibilitaram coletar as narrativas dos jovens participantes da pesquisa em cerca de cinco sessões de aproximadamente 40 minutos para cada dos sujeitos, o que ensejou aproximadamente 22 horas de gravações. O tempo e o número de encontros foram determinados pelo esgotamento de novas informações e a consecutiva repetição de relatos já apreendidos. As entrevistas foram devidamente gravadas em equipamento digital, transcritas, textualizadas e validadas pela técnica geradora de estrutura do discurso (FLICK, 2009). De posse do quadro de narrativas, com suporte no extenso universo de memórias relatadas por meio da oralidade, optou-se por utilizar a análise de conteúdo para organizar, compreender e discutir os resultados (BARDIN, 2004).

A articulação entre a metodologia da história oral para coleta dos dados e da análise de conteúdo para explorar as fontes orais permitiu desvelar e explorar uma narrativa viva, por vezes desconhecida, mas não menos importante do que tantas outras veiculadas na história oficial acerca de acontecimentos e fatos pertinentes que já não se podiam mais subtrair ou relegar aos porões das memórias (THOMPSON, 1992).

Depois da pré-análise e codificação, iniciou-se a categorização para identificar os temas principais nas narrativas (BARDIN, 2004). Esta foi estruturada de maneira organizada a fim de viabilizar uma análise mais consistente, sem perder a visão do todo. Com efeito, as informações foram assim agrupadas: 10 - juntaram-se todas as narrativas semelhantes; 2 으 agruparam-se as falas que, mesmo não sendo iguais, se assemelhavam bastante; 3ㅇ separaram-se as especificidades que não se repetiam; 4ㅇaㅁ agruparam-se finalmente os assuntos narrados em categorias definidas pela frequência com que apareciam.

Importa salientar que foi realizada leitura de outros aportes documentais prontuários com avaliações semestrais, registros observacionais e processos judiciais, com o objetivo de ampliar a compreensão dos pesquisadores sobre os jovens. Sabe-se, entretanto, que a memória, por excelência, perpassa pelo exercício da seleção e verbalização de acontecimentos pessoais, caracterizado por lembranças e esquecimentos naturais ou propositais (LE GOFF, 2003). Logo, não houve ambição de encontrar verdades inquestionáveis, e sim devolver aos leitores a imagem de mundo que reside no jovem interno, ensejando luz às experiências vivenciadas sob a óptica do pesquisado; o que não

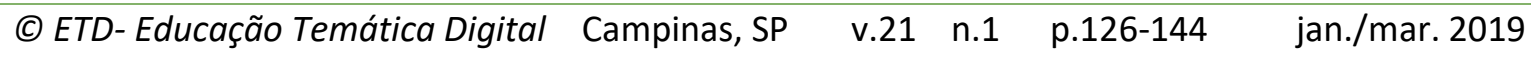


descreve uma totalidade histórica, mas possibilita realizar uma leitura dialética entre o indivíduo e o contexto social que o circunda, analisando as congruências e divergências que permeiam a educação dos jovens infratores no desenrolar da vida social (VEYNE, 1995).

\section{PERFIL DOS JOVENS PARTICIPANTES}

Exceto dois jovens, Pedro e José, que nunca haviam interrompido os estudos até a internação, os demais relataram defasagem escolar, constatada na distorção série versus idade e no depoimento que informava o abandono dos estudos. Quatro haviam frequentado a escola até os 15 anos, idade em que começaram a se envolver com a prática de atos ilícitos, e havia estudado apenas até a educação infantil. Apenas Pedro asseverou que era um bom aluno e que gostava de frequentar a escola, enquanto os demais alegaram falta de interesse pessoal. Por motivos distintos - expulsão, preguiça, comodismo ou reprovações sequenciais -, os jovens que haviam interrompido os estudos declararam que, após iniciarem a prática do ato infracional, as escolas Ihes pareciam ainda mais sem sentido e desestimulantes. Esses resultados são congruentes com os de Minayo e Souza (1997-1998) em pesquisa realizada no município de São Paulo com 934 adolescentes autores de atos infracionais, visto que, nesse estudo, a metade não estava frequentando a escola, bem como semelhantes à pesquisa de Priuli e Moraes (2007), que asseveram o perfil de ensino fundamental incompleto para os jovens internos de São José do Rio Preto.

Os jovens se inseriram precocemente no mercado de trabalho, segundo relataram, para aquisição de bens essenciais e supérfluos, fazendo com que o trabalho auferisse foco de destaque no discurso deles. Cinco haviam exercido atividades profissionais informais vendedor ambulante, auxiliar de modelista, executor de atividades agropecuárias, etc. -, iniciadas concomitantemente com a escolarização e interrompidas pelas práticas de atos infracionais ou pela apreensão e consecutiva privação de liberdade. Nesses casos, os jovens ganhavam menos de meio salário mínimo, o que demonstra o baixo nível de complexidade nas atividades e sua desvalorização. Oliveira e Assis (1999) também identificaram a iniciação precoce no trabalho informal de jovens em conflito com a lei, constatando que, até o momento da internação, $31 \%$ dos internos desenvolviam atividades de lavar e tomar conta de carro, fazer unhas, vender picolé e outras atividades ambulantes, caracterizando o subemprego dessa população.

As infrações cometidas pelos jovens que acarretaram a internação foram variadas: Pedro havia cometido um crime passional, assassinando sua namorada de maneira brutal com inúmeras punhaladas; João havia atacado com faca contra a vida de seu rival, exnamorado de sua garota, em uma briga; José havia sido detido pelo roubo de uma moto; Paulo havia sido acusado de traficar drogas, mesmo não estando nessa atividade no momento da apreensão e sendo apenas autor de roubo; Mateus havia assaltado vítimas em via pública; Felipe havia matado um jovem de gangue adversária; e Gabriel havia sido apreendido fazendo um arrastão em uma loja. Dentre os sete sujeitos, dois haviam passado 
pela delegacia apenas uma vez após a infração pela qual foram condenados, ao passo que os outros cinco já haviam sido detidos várias vezes, inclusive cumprindo outras medidas socioeducativas e reincidindo na prática ilícita.

Quanto à estrutura familiar dos jovens, observou-se que nenhum deles possuía os pais em regime conjugal habitando o mesmo lar. Três possuíam apenas a figura materna como chefe do lar; dois tinham apenas a figura paterna; e outros dois usufruíam da convivência com ambos os sexos como referência, mas, nesses casos, a figura paterna era representada por um padrasto. A ausência ou afastamento de pelo menos um dos pais, mesmo para aqueles que nem haviam chegado a conhecê-los, foi expressa nas narrativas dos jovens como algo muito significativo, o que ensejou tristeza, como demonstrado nas narrativas: "Sempre meu tio gostou de mim e foi como um pai, mas um tio não é um pai [...]" (José); "O que eu acho que podia ter mudado o rumo da minha vida era ter tido um pai" (Felipe); "Meus pais me deram para uma família que morava lá perto quando eu era pequeno, não me quiseram" (Paulo); "Não moro com minha mãe por causa do companheiro que ela está agora, ele não quer nós morando com ela [Mateus e seu irmão] porque ele sabe que fomos presos, que nós roubamos. Ele não gosta de nós, não" (Mateus).

As mudanças na composição familiar puderam ser verificadas pela sucessão de cuidadores: mãe, avó, pai, padrasto e pais adotivos; ou pela falta desses. Assis e Constantino (2001) caracterizam esse fenômeno como pingue-pongue emocional, indicando que os jovens foram empurrados de um lado para outro durante a infância. Paulo, Mateus e Gabriel, inclusive, relataram que já haviam mudado de lar três vezes, sem haver pelo menos uma mesma figura de referência constante permanecendo ao lado deles. Sob esse viés, a família, núcleo que deveria ser principal fonte de apoio, educação e afeto, não possibilita que seus membros adquiram senso de estabilidade e permanência (BRANCO; WAGNER; DEMARCHI, 2008). Afetada a estabilidade, em muitos casos, há uma vivência de condições e limites diferentes que dificultam a compreensão acerca de algumas condutas, ou seja, perde-se uma orientação educacional mais retilínea e corre-se o risco de fragilizar laços afetivos, relativizar limites impostos e consequentemente normas de conduta social (DELL'AGLIO; SANTOS; BORGES, 2004). Torna-se essencial, então, fortalecer relações entre os integrantes, pois uma relação familiar dialógica com membros participativos minimiza a incidência do comportamento antissocial (EIZIRIK; BERGMANN, 2004; FEIJÓ; ASSIS, 2004; PACHECO; HUTZ, 2009).

No tocante às condições financeiras, constatou-se que as profissões dos genitores e a renda das famílias dos jovens eram oriundas de atividades mal remuneradas e informais. O trabalho doméstico nos serviços gerais de limpeza era o mais predominante, seguido de aposentadorias; apenas um genitor possuía emprego formal estável. Os jovens, dessa maneira, eram de baixa renda; sendo assim, apesar do contexto de pobreza não ser fator 
determinante para o cometimento de infrações, é com suporte nesse quadro que qualquer leitura e estudo sobre a violência na juventude precisam se realizar (PRIULI; MORAES, 2007; VOLPI, 2001). Reguera (2005) explica que, para quem tem algo a perder, um assalto, por exemplo, representa um grande risco que não compensa correr, mas, para aqueles que já vivem com tão pouco, o risco se torna mais viável.

A desagregação familiar e a situação socioeconômica desfavorável são fatores de vulnerabilidade para o conflito com a lei entre jovens, como comprovado em pesquisas anteriores a esta (FEIJÓ; ASSIS, 2004; SANABRIA; RODRÍGUEZ, 2009). Esses aspectos, na perspectiva dos jovens, não foram os fatores principais de motivação ao ato infracional, pois eles alegaram que a iniciação havia se dado mediante descontrole emocional nos casos de violência decorrentes de conflitos amorosos, influência de amigos e desejo de adquirir objetos de desejo.

\section{A EXPERIÊNCIA DE INTERNAÇÃO: ANÁLISE CATEGÓRICA DOS RESULTADOS}

A análise de conteúdo viabilizou a identificação de cinco categorias atinentes à experiência de internação - violência sofrida, identidade infratora, perspectivas e planos dos jovens, código de ética e significado da internação.

Na categoria violência sofrida, não houve relatos de maus-tratos na infância, mas todos os jovens comentaram a respeito da vivência de agressões físicas, seja de maneira direta, como vítimas, ou indireta, como espectadores. As agressões citadas foram, na sua totalidade, praticadas por policiais ou pelos instrutores do CEPA. Dentre os sete jovens, quatro afirmaram que haviam sofrido violência física, já os demais informaram que não haviam sido agredidos, porém relataram que já haviam assistido pelo menos a uma cena de agressão praticada contra seus colegas, o que contradiz o princípio educativo da socioeducação:

\footnotetext{
Assim que eu me soltei, eu parei, tinha deixado mais de roubar, ficava só em casa, saindo com minha namorada, mas, quando eu tava no banco da praça, os canas vinha me buscar, me dava uma pisa e me soltava de volta; me pegava nos cantos, levava pros matos e dava uma pisa. Quando a escolta entra, é caso sério, corre até bala. Quando tem vistoria dos canas, tem que ficar pelado de costa e sempre leva peia, os orientadores aproveitam e batem também. (Mateus).

Aí foi quando fui preso no São Miguel por roubo, porque lá tinha uns três policiais que não davam valor a eu não, era o Jorge e o Emanuel, toda vez que me pegavam, me batia. (Felipe).

Me derrubaram no chão e começaram a bater assim que confirmaram que era eu quem eles procuravam. Mas, no meio do caminho, pararam a viatura e começaram a me espancar com cassetete. Como não dizia onde estava a arma do crime, eles me batiam todos os dias. Eles me batiam demais, todo dia, eu até desmaiava. Arrancaram todas as minhas unhas. Aí eu entreguei, disse onde estava porque não aguentava mais apanhar. (Pedro).
}

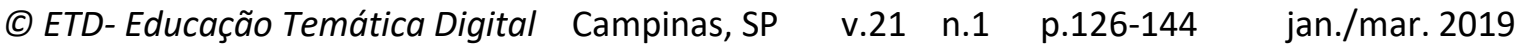


Juntamente com os relatos dos tratamentos agressivos, há a tranca, um espaço de isolamento da Instituição que possui também grande representação simbólica para os internos entrevistados. Felipe assim a descreveu: "Você não vê o lado de fora, tudo trancado, isolado, e, dependendo, você fica sem colchão se o cara ficar bagunçando muito. Na tranca é ruim porque não faz atividade [...]. A chibata é só uma vez, mas, se bagunçar, é todo dia".

Ao invés de zelar pela dignidade dos jovens, "[...] pondo-os a salvo de qualquer tratamento desumano, violento, aterrorizante, vexatório ou constrangedor [...]" (ECA, art. 18), constataram-se o desrespeito aos direitos humanos e o ceticismo no tocante à mudança de atitude dos jovens (ESPÍNDULA; SANTOS, 2004). As práticas arcaicas e desumanas de suplício do corpo praticadas no interior de instituição socioeducativa e fora desta por profissionais que deveriam ser exemplos de retidão e ética exprimem maior ênfase à punição do que à educação e não colaboram com o desenvolvimento de uma vida cidadã (FOUCAULT, 2009).

No que se refere à identidade infratora, constatou-se que os agentes de um ou de poucos atos infracionais não se percebiam como infratores, mas os que mais habitualmente se envolviam em situações irregulares já se mostravam como desviantes, como se pode averiguar comparando os depoimentos: "Eu acho que não sou ruim, me entreguei e não me arrependi. Eu matei, mas não sou assassino, não; não sei o que deu em mim, não vou nunca mais fazer isso" (Pedro); "Eu sou ladrão e matador, já dei cabo num monte de gente; eu sou o atirador, quem mata mesmo, não tenho pena, não" (Felipe); "Sou um, cinco, cinco, né? Não trabalho porque sou preguiçoso mesmo, tiro mais roubando" (José). A diferença nos discursos consiste na percepção que cada um fez de si. Os iniciantes não se enxergavam como infratores, os quais relataram que iriam mudar; já os mais experientes se concebiam como "ladrões", "matadores", dentre outros, internalizando a condição de infratores.

Nesse sentido, observou-se que, ao estabelecerem uma carreira infracional, identificam-se e dificilmente conseguem reverter essa trajetória (PEREIRA; SUDBRACK, 2008). Importa considerar que "[...] o efeito político-social esperado pela aplicação de uma medida socioeducativa não caminha sem a consideração do mais singular e íntimo de cada adolescente, do qual sua posição subjetiva faz testemunho [...]", logo faz-se necessário considerar as percepções dos jovens e os modos de fazer exceção à regra e habitar o mundo (GUERRA et al., 2014, p. 171).

Quanto às perspectivas e planos dos jovens, averiguou-se que a maioria possuía interesse em mudar suas atitudes e trilhar um percurso de vida consoante a cidadania e os bons costumes, não mais reincidindo na prática de atos infracionais, como asseveram Guillén e Nascimento (2010) e Manso e Almeida (2009). Os relatos apontaram: "Quando sair daqui, vou morar em Fortaleza, longe de lá. Vou começar uma vida nova" (João); "Aqui

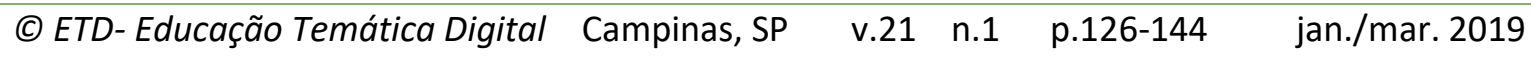


estou pagando pelo que fiz; quando voltar, vou continuar minha vida, estudando e trabalhando" (Pedro); "Quando sair daqui, vou trabalhar e criar meu filho, quero ser um bom pai para ele, o pai que eu não tive" (Felipe); "Quando sair daqui, vou tentar estudar e trabalhar, essa vida não dá mais, não. Mas é difícil” (José); "Quando eu sair, vou tentar não me envolver mais nisso, estou ficando de maior e não venho mais para cá, não" (Gabriel).

Sabe-se, no entanto, que as condições encontradas na liberdade, bem como as situações de vida na comunidade, lócus importante de educação não formal e informal, são variadas, repletas de vulnerabilidades (BRANCO; WAGNER, 2009). E as fragilidades, somatizadas pela falta de educação formal e profissionalização de qualidade na socioeducação, bem como de acompanhamento eficaz ao egresso do sistema socioeducativo, por vezes, não permitem que o jovem desenvolva seus objetivos de vida como gostaria e acabe por não conseguir concretizar seus planos (OLIVEIRA; ASSIS, 1999). O interesse do jovem pela reinserção social, contudo, em moldes diferentes dos que eram vivenciados, é uma sinalização positiva para que possa haver mudança de condutas, como também para fomento em investimento público voltado a uma educação de qualidade para os jovens privados de liberdade.

No que concerne à categoria código de ética, observou-se que os jovens elaboravam um conjunto de regras válido entre seus pares internos. Mesmo, porém, infringindo as determinações legais e considerando-as letra morta, eles demonstraram que conseguiam elaborar as próprias normas, constituindo uma legislação costumeira, com linguagem específica, para um universo à parte do contexto global, o espaço da reclusão. Eles estipulavam ações permitidas - matar policial, realizar grandes assaltos, comandar um ponto de venda de drogas, liderar rebelião e motins [...] - e proibidas - bater em mulher, matar mulher, delatar um colega, estuprar, matar criança, desrespeitar a mãe [...] - no submundo da infração. Aqueles que discordarem das referidas normas, violando-as, passam por um julgamento silencioso, mas significativamente rígido, em que a punição é efetivada com o suplício do corpo, martírio ou pena de morte. Ante a intensa fiscalização na Instituição, foi possível presenciar, ao longo da pesquisa, o assassinato por sufocamento de um jovem estuprador e o espancamento de um delator, fato comprovativo de que os internos faziam valer, com as devidas punições, o cumprimento do código de ética por eles instituído.

Quanto à última categoria, significado da internação, percebeu-se que as experiências vivenciadas na infância, as condições de vida, as relações interpessoais com a família, amigos e demais membros da comunidade, as oportunidades desfrutadas, a escolarização e tantas outras facetas interferem sobremaneira na compreensão pessoal da internação e sua interface com a educação, que se configura individual, intransferível e não generalizável (MANSO; ALMEIDA, 2009). Nessa lógica, o ato infracional cometido e a experiência de internação podem assumir significados diversos: "[...] dar destaque ao adolescente, principalmente se tiver uma grande repercussão social” (FREITAS, 2008-2009, 
p. 43); ser meramente punitiva e aparentemente sem sentido; propiciar uma oportunidade para reflexão e estímulo para mudar de vida; ser apenas estigmatizante e prejudicial; suscitar um momento propício para o encontro com Jesus; dentre outros. Pôde-se perceber que a visão acerca da educação na experiência de internação era diferente e única para cada um dos sete jovens, como será explicitado nos parágrafos adiante.

Pedro - que possuía uma vida tranquila em cidade do interior e havia sido educado junto com uma família equilibrada e amorosa - considerou o seu ato ilícito, o assassinato da sua paixão com mais de 20 punhaladas, como uma atrocidade quase inacreditável. 0 arrependimento lhe tomou conta de tal maneira que o garoto concebia a internação como positiva, pois acreditava que, apesar do prejuízo na escolarização, sua ação havia sido monstruosa, a qual merecia ser punida. Nesse caso, a internação era vista pelo interno como punitiva, mas benéfica, porque lhe fazia refletir sobre seus atos e fortalecer sua fé, como ele próprio relatou:

A internação no CEPA serviu, porque antes eu não lia a Bíblia e agora todo dia eu leio a Bíblia, agora eu sei o que é a palavra de Deus. Eu acho que ficar internado pra mim melhora a situação, porque a gente tá pagando pelo ato que fez e serve para refletir não só isso, mas outras coisas também.

Para João - que possuía uma família numerosa e pouco atenciosa, que já não estudava e que era acostumado com uma vida sem limites -, a internação possuía uma vertente positiva e outra negativa, sendo esta última mais preponderante. A positiva era decorrente do fato de poder estudar e participar de atividades profissionalizantes, vivências consideradas úteis, mas não praticadas na liberdade. A negativa era oriunda do fato de que sentia grande dificuldade em viver sob rígida disciplina, além do estigma que carregaria consigo ante a sociedade quando saísse, como ele mesmo ponderou:

O positivo é que eu faço curso, participo de oficina e estudo para aprender alguma coisa. [...] O negativo é a perda de tempo, que eu poderia estar fazendo outras coisas lá fora. Passar por aqui só piora, porque você fica com o nome sujo, as pessoas sabem que você foi preso. Só atrapalha a vida do cara, não ajuda em nada.

José - filho único de pai desconhecido, bem assistido pela mãe, avó e tio, que havia estudado em colégio particular e possuía uma vida mais confortável - acreditava que os atos infracionais, furtos e roubos, eram vantajosos; ele disse que os praticava por diversão e interesse em conseguir mais bens materiais. Nesse caso, a internação era concebida por ele como negativa em todos os aspectos: não the oferecia escolarização com a mesma qualidade que a experimentada na liberdade, não o preparava para o mercado de trabalho com o qual possuía afinidade, não Ihe possibilitava oportunidades concretas de avaliar as consequências de seus atos e apenas servia para puni-lo, fazendo-lhe perder tempo. Somando-se a isso, ainda ensejava ampliar as amizades delitivas e o campo de atuação para o roubo, possibilitando tornar-se ainda mais respeitado e considerado no meio infracional, como ele narrou:

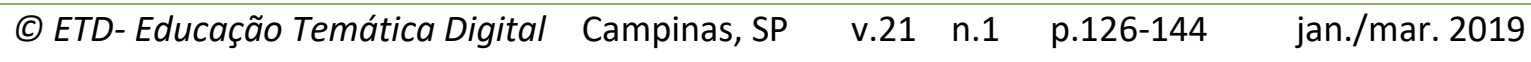


Isso, para mim, só serve para perder tempo, porque minha vida continua do mesmo jeito. Eu aprendo é mais, a cabeça fica melhor. Eu mudo as amizades, os caras consideram mais eu. Eu saio e fico com mais consideração pelo que eu fiz, que não é qualquer um que faz, não entreguei o outro. Já sabem que eu vou sair, eles sabem que sou limpeza, falam de mim. [...] Não sei como é que vou fazer para sair dessa vida, porque é um vício. Aqui o cara encontra uns caras com a mente mais elevada igual a nossa, encontra oferta para ganhar mais, e o cara fica pensando no dinheiro. O cara rouba três carros em um dia e tira mais de dez mil em um dia só.

Paulo - abandonado pelos pais biológicos, vivia um pingue-pongue familiar entre a vida com uma mãe ex-presidiária fugitiva e sua numerosa família adotiva - havia experimentado a dura realidade de ter que sustentar uma casa com seus esforços, não adquirindo o sucesso almejado com seus atos ilícitos. Por esses motivos, acreditava que seus atos infracionais, furto e roubo, eram incorretos, mas necessários, e que a internação só apresentava aspectos negativos, por não propiciar apoio suficiente, acompanhamento ao egresso e possibilidade de escolarização de qualidade, o que proporcionaria a esse indivíduo uma mudança de vida, como explicou:

\begin{abstract}
Aqui serve para perder tempo e refletir tudo que perde na liberta; aqui eu fico pensando que esse mundo não dá para ninguém, não. A gente vê como a vida é cruel. [...] Quando sair daqui, vou tentar estudar e trabalhar; essa vida não dá mais, não. Mas é difícil. [...] Passar por essas casas não faz ninguém mudar de vida, não; já entrei e saí umas vezes e não mudou nada. Ninguém vai ajudar você lá fora, não. Quem se preocupa se você e sua família estão tendo o que comer? De ajudar a conseguir emprego e estudo? De nós não voltar para as drogas?
\end{abstract}

Mateus - que havia perdido o pai bruscamente e tinha sido abandonado pela mãe por ser estigmatizado como delinquente pelo padrasto, vivendo entre a casa das duas avós , apesar de ter sofrido constantes violências físicas de policiais e instrutores, ponderou que considerava seus atos infracionais indevidos, furtar e roubar, no entanto concebia a internação como negativa, porque acentuava a revolta e não proporcionava meios concretos para fazer com que os jovens obtivessem progresso no âmbito educacional e adotassem atitudes distintas, como verbalizou: "A minha passagem pelo CEPA é ruim, mas é melhor se conformar e a achar bom, porque senão fica pior ainda. [...] Isso aqui não muda em nada, não; não educa ninguém, não; tem gente que sai é pior, endoida ficar aqui dentro".

Felipe - que vivia apenas com sua mãe viúva, quem passava o dia fora de casa trabalhando como faxineira e não lhe dava a atenção e educação necessárias - contou que era ainda pequeno quando teve o pai assassinado e que nunca havia tido uma figura paterna, sendo sua irmã mais velha o seu maior apoio, mas ela saiu de casa ao casar. Praticamente sozinho, longe de qualquer olhar atento, Felipe virou integrante de uma gangue do bairro. Para ele, seus atos ilícitos eram importantes para obter aceitação e respeito entre seus pares, mas financeiramente não compensavam. Desse modo, a experiência de internação possuía uma vertente positiva e outra negativa. Ele acreditava que a vantagem consistia no fato de poder refletir acerca do seu futuro e objetivos de vida,

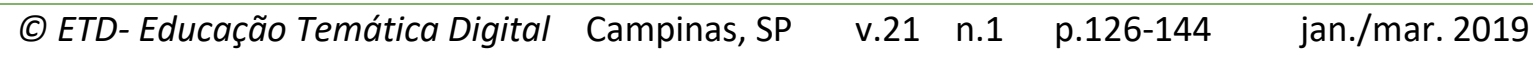


além de the possibilitar mais moral com seus pares. A desvantagem pautava-se no argumento de que a internação era demorada, fazendo o jovem perder tempo que poderia estar sendo investido nas relações familiares, na escolarização e em outras ações mais relevantes, como expressou:

A minha passagem nessa instituição representa muita coisa, pra mim eu acho que é ruim e é bom. [...] O bom é poder ser mais considerado pelos parceiros e parar para pensar no que fez. O ruim é que você passa muito tempo preso com uma ruma de macho e perde de estar com a família, perde de estudar e perde adolescência, namorada.

Gabriel - paupérrimo, analfabeto, com séria dificuldade em articular ideias e se relacionar, não estudava antes de entrar na Instituição e passava o dia ajudando os pais e brincando na comunidade - foi o garoto mais difícil de ser compreendido, justamente por conta da pouca capacidade de narrar acontecimentos e a própria história de vida de maneira coerente. Gabriel não conseguia verbalizar com clareza sua opinião sobre a educação na experiência de privação de liberdade, mas foi possível perceber que ele considerava seus atos infracionais errados e pouco vantajosos, já que não conseguia benefícios importantes por intermédio deles. Ele relatou que os praticava para acompanhar os colegas. Com suporte nessa vivência, ele pôde perceber que roubar, no seu caso, não compensava e decidiu parar de participar dessas práticas ilegais, como tentou esclarecer:

O tempo que passei aqui dentro não acho perca de tempo, porque tem uns que sai, vê que não dá jeito, aí faz de novo. [...] Dessa vez que eu sair, não quero mais, não [roubar], vou procurar algo para fazer, vou ficar de maior. Roubei e não consegui nada. Tentei estudar e não deu certo. Agora vou trabalhar.

A interpretação de cada jovem acerca da experiência de privação de liberdade e da educação variava de acordo com a sua história de vida, de tal modo que, para dois jovens Pedro e Gabriel -, a vivência foi considerada totalmente positiva, porque enxergavam na internação a possibilidade de pagar pelos atos ilícitos cometidos e posteriormente desfrutar da liberdade em consonância com a cidadania democrática. Para outros três - José, Paulo e Mateus -, a experiência foi considerada totalmente negativa, porque não lhes oferecia condições de educação, profissionalização e atendimento que viabilizassem mudança de conduta, além de lhes ensejar sentimento de revolta. Já João e Felipe percebiam aspectos negativos e positivos na internação: os primeiros diziam respeito às precárias condições de internação, que não propiciavam crescimento escolar ou profissional, resumindo-se à perda de tempo com prejuízo nas relações interpessoais e atraso na escolarização; já os aspectos positivos se sustentavam na possibilidade de refletir sobre as ações praticadas, ganhar mais respeito entre seus pares, ampliar contatos para receptação de mercadorias roubadas e aprender outras técnicas mais lucrativas.

Nessa direção, pode-se dizer que, para cinco dos sete jovens, a privação de liberdade possuía apenas conotação negativa, haja vista que as vantagens citadas não podem ser assim consideradas na percepção da socioeducação. Apenas um jovem considerou como aspectos positivos a escolarização e a profissionalização oferecidas pelo CEPA, mas, nesse
(C) ETD- Educação Temática Digital
Campinas, SP

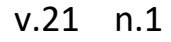
p.126-144
jan./mar. 2019 
caso, o garoto praticamente nunca havia frequentado a escola nem trabalhado regularmente, usufruindo de seu tempo de maneira ociosa.

Importa salientar que todos os jovens, mesmo os que apontaram aspectos positivos na internação, demonstraram que consideravam a privação de liberdade como punitiva, e não como educativa. Logo, para eles, os objetivos primeiros não se vinculavam ao desenvolvimento, ao acompanhamento ou à ressocialização, mas à repressão, à punição e ao disciplinamento, sendo os efeitos da institucionalização o isolamento, a exclusão e a estigmatização, de tal modo que "[...] o espaço da unidade representa o palco de uma violência normatizada, construída nas entrelinhas dos discursos, nos silêncios, nas linhas de fuga e principalmente nos pactos de alianças" (FREITAS, 2008-2009, p. 49). Eles mantinham uma concepção heterônoma das leis, por acreditarem que as tinham de cumprir por ser uma obrigação e pelo receio de serem repreendidos. Ademais, nessa perspectiva autoritária, há uma visível inexistência de senso crítico acerca do surgimento, objetivo ou funcionalidade das regras instituídas.

Em razão da maneira como os jovens compreendiam a privação de liberdade, podese deduzir que essa medida não cumpre sua função social de educar ou regenerar tais sujeitos para o convívio harmônico em liberdade, representando muito mais um isolamento do que um resgate social (BRASIL, 2006). Ao considerar a maneira como vem sendo desenvolvida, é necessário combater o faz de conta da socioeducação, não encrudelecendo punições ou reduzindo a maioridade penal, mas efetivando ações concretas de atendimento, acompanhamento e suporte aos jovens em suas especificidades com responsabilidade. Afinal, ressocializar seria simultaneamente o resultado de esforços pessoais dos jovens internos e de uma configuração social mais justa e igualitária (BARCINSKI; CUNICO; BRASIL, 2017).

\section{5 ÚLTIMAS REFLEXÕES}

O objetivo foi compreender as percepções juvenis atinentes ao significado da experiência socioeducativa de internação, medida privativa de liberdade que se propõe a ser educativa e socializadora. Para contemplar esse escopo, utilizou-se a história oral com sete jovens em conflito com a lei, institucionalizados, para coletar as subjetividades juvenis. Essas fontes foram desveladas mediante a análise de conteúdo das narrativas textualizadas, para as quais emergiram cinco categorias, a saber: violência sofrida, identidade infratora, perspectivas e planos dos jovens, código de ética e significado da internação.

Constatou-se, entretanto, que há inúmeras facetas imbricadas na dinâmica trajetória de vida dos jovens e na complexa experiência de internação que apontam para perpetuar a exclusão social. O processo socioeducativo caracterizado na prática pelo autoritarismo e violação de direitos, de um modo geral, não desenvolve uma sociabilidade mais compatível com a cidadania democrática, reforça a marginalização e identidade infratora dos jovens, fragiliza as relações interpessoais, prejudica a escolarização, enseja sentimento de revolta e

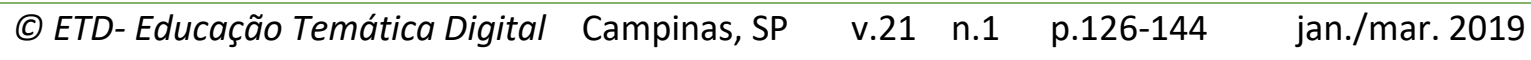


insatisfação, fomenta o egocentrismo e não propicia condições reais de mudança de comportamento, configurando-se, na percepção dos jovens, como uma perda de tempo sem sentido. As estratégias sociopedagógicas não surtem o efeito esperado e a educação aufere espaço secundário no ambiente privativo de liberdade (AGUINSKY; CAPITÃO, 2008).

Percebe-se, desse modo, que as internações possuem sanções que não restringem apenas a liberdade desses sujeitos ao convívio com seus familiares e com a sociedade como um todo, mas também a própria liberdade do corpo e o acesso à educação formal em quantidade mínima de horas diárias. Tais jovens passam por privações penosas dentro do espaço de internação, que vão da falta de estrutura adequada à superlotação e ao despreparo dos instrutores educacionais para com o tratamento dirigido a tais sujeitos. Enfim, esses jovens passam por verdadeiros tempos de prova que perduram por todo 0 cumprimento da medida socioeducativa em meio fechado (FOUCAULT, 2009).

Faz-se necessário efetivar melhor atendimento e acompanhamento às famílias, principalmente em situação de vulnerabilidade social, efetuar ações de fortalecimento de vínculos e protagonismo comunitário, priorizar as medidas socioeducativas em meio aberto, fortalecer a qualidade da educação formal durante o cumprimento de medidas socioeducativas de privação de liberdade, viabilizar um trabalho comprometido e eficiente que envolva a sociedade na condição de corresponsável do Estado e possibilitar intervenções educativas baseadas no diálogo e interação de vítimas e infratores, ensejando a troca de experiências e a apropriação dos sentimentos alheios (AGUINSKY; CAPITÃO, 2008; PRIULI; MORAES, 2007; SPOSITO, 2000). Compreende-se, entretanto, que a infração na juventude é um processo complexo, multifacetado e plural, logo esta pesquisa permite inferir que há necessidade de se repensar o modelo de prevenção à conduta infracional, de repressão e de punição por meio da internação e do acompanhamento ao egresso do sistema socioeducativo, pois, nos moldes como se desenvolve, precariza ainda mais a escolarização, acentua a exclusão e não combate a reincidência.

Ensejando ouvir os excluídos, este estudo se propôs muito mais a levantar hipóteses do que a oferecer respostas. Esta pesquisa pôde inferir que a punição exercida pelo Estado e sua forma organizacional são caracterizadas pela primazia à ordem, à disciplina, ao enquadramento, à aceitação silenciosa de regras impostas e à anulação do sujeito, muito embora o discurso oficial defenda o combate à criminalidade e a instituição como espaço de educação e ressocialização do jovem. Tal postulado suscita a ideia de que a prática de atos infracionais entre jovens brasileiros ainda é um campo à espera de investigação científica e de visibilidade dos organismos sociais. Afinal, ainda que a história da humanidade transite pela violência, é importante atentar para a calamidade já instaurada e refletir sobre o contexto atual como lócus de uma crise que não pode se naturalizar e precisa ser constantemente discutida, pensada e desvelada no intuito de minimizar consequências danosas (SOUSA; GOLDMEIER, 2008).

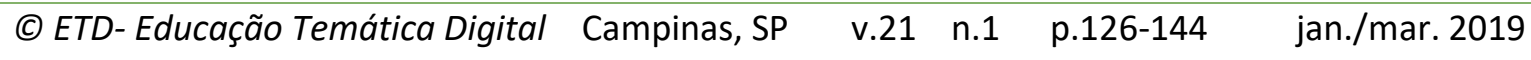




\section{REFERÊNCIAS}

AGUINSKY, Beatriz; CAPITÃO, Lúcia. Violência e socioeducação: uma interpelação ética a partir de contribuições da justiça restaurativa. Revista Katálysis, Santa Catarina, v. 11, n. 2, p. 257-264, 2008. Disponível em: http://www.scielo.br/scielo.php?pid=S1414-

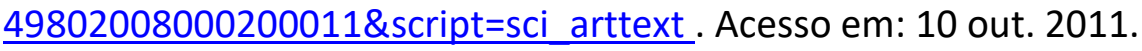

ALMEIDA, Nemésio Dario Vieira de. Análise dos homicídios em Pernambuco e as contribuições da justiça restaurativa. Psicologia: Ciência e Profissão, Brasília, DF, v. 37, n. 3, p. 565-578, 2017. Disponível em: http://www.scielo.br/scielo.php?script=sci arttext\&pid=S141498932017000300565\&lng=pt\&nrm=iso . Acesso em: 18 jun. 2018.

ASSIS, Simone Gonçalves de; CONSTANTINO, Patrícia. Filhas do mundo: infração juvenil feminina no Rio de Janeiro. Rio de Janeiro: Fiocruz, 2001.

ASSIS, Simone Gonçalves de; SOUSA, Edinilsa Ramos de. Criando Caim e Abel - Pensando a prevenção da infração juvenil. Ciência \& Saúde Coletiva, Rio de Janeiro, v. 4, n. 1, p. 131144, 1999. Disponível em:

http://www.scielo.br/scielo.php?script=sci nlinks\&ref=000153\&pid=S14138123200900020002400019\&Ing=en Acesso em: 16 jun. 2018.

BARCINSKI, Mariana; CUNICO, Sabrina Daiana; BRASIL, Marina Valentim. Significados da ressocialização para agentes penitenciárias em uma prisão feminina: entre o cuidado e o controle. Trends in Psychology, Ribeirão Preto, v. 25, n. 3, p. 1257-1269, 2017. Disponível em: http://www.scielo.br/scielo.php?script=sci arttext\&pid=S2358$18832017000301257 \&$ lng=pt\&nrm=iso . Acesso em: 18 jun. 2018.

BARDIN, Laurence. Análise de conteúdo. 3. ed. Lisboa: 70, 2004.

BRANCO, Bianca de Moraes; WAGNER, Adriana. Os adolescentes infratores e o empobrecimento da rede social quando do retorno à comunidade. Ciência \& Saúde Coletiva, Rio de Janeiro, v. 14, n. 2, p. 557-566, 2009. Disponível em: http://www.scielo.br/scielo.php?pid=S1413-81232009000200024\&script=sci arttext. Acesso em: 17 jun. 1018.

BRANCO, Bianca de Moraes; WAGNER, Adriana; DEMARCHI, Karina Ariani. Adolescentes infratores: rede social e funcionamento familiar. Psicologia: Reflexão Crítica, Porto Alegre,

v. 21, n. 1, p. 125-132, 2008. Disponível em:

http://www.scielo.br/scielo.php?script=sci nlinks\&ref=000123\&pid=S01023772201200020000600006\&lng=en . Acesso em: 10 out. 2011.

BRASIL. Lei no 8.069, de 13 de julho de 1990. Dispõe sobre o Estatuto da Criança e do Adolescente e dá outras providências. Diário Oficial [da] República Federativa do Brasil, Poder Executivo, Brasília, DF, 16 jul. 1990..

BRASIL. Presidência da República. Secretaria Especial dos Direitos Humanos. Conselho Nacional dos Direitos da Criança e do Adolescente. Sistema Nacional de Atendimento Socioeducativo - SINASE. Brasília-DF: Conanda, 2006. Disponível em: http://www.conselhodacrianca.al.gov.br/sala-de-imprensa/publicacoes/sinase.pdf. Acesso em: 18 jun. 2018.

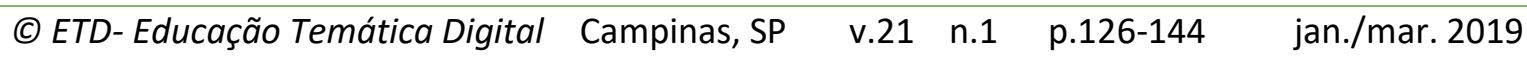


CANETTI, Ana Lúcia; MAHEIRIE, Kátia. Juventudes e violências: implicações éticas e políticas. Factal: Revista de Psicologia, Rio de Janeiro, v. 22, n. 3, p. 573-590, 2010. Disponível em: http://www.scielo.br/scielo.php?script=sci arttext\&pid=S1984-02922010000900009 . Acesso em: 18 jun. 2018.

DELL'AGLIO, Débora Dalbosco; SANTOS, Samara Silva dos; BORGES, Jeane Lessinger. Infração juvenil feminina: uma trajetória de abandonos. Interação em Psicologia, Curitiba, v. 8, n. 2, p. 191-198, 2004. Disponível em: https://revistas.ufpr.br/psicologia/article/download/3255/2615 . Acesso em: 20 jun. 2018. EDUARDO, Lara de Paula; EGRY, Emiko Yoshikawa. Estatuto da Criança e do Adolescente: a visão dos trabalhadores sobre sua prática. Revista da Escola de Enfermagem da USP, São Paulo, v. 44, n. 1, p. 18-24, 2010. Disponível em: http://www.scielo.br/scielo.php?pid=S008062342010000100003\&script=sci abstract\&tlng=pt . Acesso em: 10 out. 2012.

EIZIRIK, Mariana; BERGMANN, David Simon. Ausência paterna e sua repercussão no desenvolvimento da criança e do adolescente: um relato de caso. Revista de Psiquiatria do Rio Grande do Sul, Porto Alegre, v. 26, n. 3, p. 330-336, 2004. Disponível em:

http://www.scielo.br/scielo.php?pid=S0101-81082004000300010\&script=sci arttext Acesso em: 20 jun. 2018.

ESPÍNDULA, Daniel Henrique Pereira; SANTOS, Maria de Fátima de Souza. Representação sobre a adolescência a partir da ótica dos educadores sociais de adolescentes em conflito com a lei. Psicologia em Estudo, Maringá, v. 9, n. 3, p. 357-367, 2004. Disponível em: http://www.scielo.br/pdf/pe/v9n3/v9n3a03.pdf Acesso em: 10 out. 2010.

FEIJÓ, Maria Cristina; ASSIS, Simone Gonçalves de. O contexto de exclusão social e de vulnerabilidades de jovens infratores e de suas famílias. Estudos de Psicologia, Natal, v. 9, n. 1, p. 157-166, 2004. Disponível em: http://www.scielo.br/pdf/epsic/v9n1/22391.pdf. Acesso em: 20 jun. 2018.

FERREIRA, Marieta de Moraes; AMADO, Janaína (Org.). Usos \& abusos da história oral. 8. ed. Rio de Janeiro: FGV, 2006.

FIALHO, Lia Machado Fiuza. A vida de jovens infratores privados de liberdade. Fortaleza: UFC, 2015a.

FIALHO, Lia Machado Fiuza. Biografia de um jovem traficante. Fortaleza: UFC, 2015b.

FLICK, Uwe. Introdução à pesquisa qualitativa. 3. ed. Porto Alegre: Artmed, 2009.

FOUCAULT, Michel. Vigiar e punir: nascimento da prisão. 37. ed. Petrópolis: Vozes, 2009.

FREITAS, Rilda Bezerra de. Códigos de honra: um estudo sobre adolescentes privados de liberdade em Fortaleza-CE. Educação em Debate, Fortaleza, v. 1-2, n. 56-58, p. 37-52. 20082009. Disponível em:

http://www.repositorio.ufc.br/bitstream/riufc/15448/1/2008 art rbezerra.pdf . Acesso em: 20 jun. 2018.

GUERRA, Andréa Maris Campos et al. Risco e Sinthome: a psicanálise no sistema socioeducativo. Psicologia: Teoria e Pesquisa, Brasília, DF, v. 30, n. 2, p. 171-177, 2014.
(C) ETD- Educação Temática Digital
Campinas, SP
v.21 n.1
p.126-144
jan./mar. 2019 
Disponível em: http://www.scielo.br/scielo.php?script=sci arttext\&pid=S0102-

37722014000200006\&lng=pt\&nrm=iso . Acesso em: 18 jun. 2018.

GUILLÉN, Rosa Riofrío; NASCIMENTO, Lucila Castanheira. Consumo de drogas en los jóvenes de la ciudad de Guayaquil, Ecuador. Revista Latino-Americana de Enfermagem, Ribeirão Preto, v. 18, n. esp., p. 598-605, 2010. Disponível em:

www.scielo.br/scielo.php?script=sci arttext\&pid=S0104-11692010000700016 . Acesso em: 20 jun. 2018.

LE GOFF, Jacques. História e memória. 5. ed. Campinas: Unicamp, 2003.

MANSO, Ana; ALMEIDA, Ana Tomás de. Um discurso a duas vozes: potencialidades de um estudo interpretativo sobre lei e institucionalização. Psicologia: Reflexão e Crítica, Porto Alegre, v. 22, n. 3, p. 455-465, 2009. Disponível em: http://www.scielo.br/scielo.php?pid=S0102-79722009000300017\&script=sci arttext . Acesso em: 23 jun. 2018.

MEIHY, José Carlos Sebe Bom; RIBEIRO, Suzana L. Salgado. Guia prático da história oral. São Paulo: Contexto, 2011.

MESQUITA, Ilka Miglio de; FONSECA, Selva Guimarães. Formação de professores de História: experiências, olhares e possibilidades. História Unisinos, São Leopoldo, v. 10, n. 3, p. 333343, 2006. Disponível em: http://revistas.unisinos.br/index.php/historia/article/view/6187 . Acesso em: 20 jun. 2018.

MINAYO, Maria Cecília de Souza; SOUZA, Edinilsa Ramos de. Violência e saúde como um campo interdisciplinar e de ação coletiva. História, Ciências, Saúde, Manguinhos, v. 4, n. 3, p. 513-531, 1997-1998. Disponível em: www.scielo.br/pdf/hcsm/v4n3/v4n3a06.pdf . Acesso em: 20 jun. 2018.

MONTENEGRO, Antonio Torres. História oral e memória: a cultura popular revisitada. 6. ed. São Paulo: Contexto, 2007.

OLIVEIRA, Maruza; ASSIS, Simone. Os adolescentes infratores do Rio de Janeiro e as instituições que os "ressocializam". A perpetuação do descaso. Cadernos de Saúde Pública, Rio de Janeiro, v. 15, n. 4, p. 831-844, 1999. Disponível em: http://www.scielo.br/scielo.php?script=sci_arttext\&pid=S0102-311X1999000400017. Acesso em: 20 jun. 2018.

PACHECO, Janaína Thaís Barbosa; HUTZ, Claudio Simon. Variáveis familiares preditoras do comportamento anti-social em adolescentes autores de atos infracionais. Psicologia: Teoria e Pesquisa, Brasília, DF, v. 25, n. 2, p. 213-219, 2009. Disponível em: http://www.scielo.br/pdf/ptp/v25n2/a09v25n2.pdf. Acesso em: 20 jun. 2018.

PEREIRA, Sandra Eni Fernandes Nunes; SUDBRACK, Maria Fátima Olivier. Drogadição e atos infracionais na voz de adolescentes em conflito com a lei. Psicologia: Teoria e Pesquisa, Brasília, DF, v. 24, n. 2, p. 151-159, 2008. Disponível em:

http://www.scielo.br/scielo.php?pid=S010237722008000200004\&script=sci abstract\&tIng=pt. Acesso em: 20 jun. 2018.

PRIULI, Roseana Mara Aredes; MORAES, Maria Silva de. Adolescentes em conflito com a lei. Ciência \& Saúde Coletiva, Rio de Janeiro, v. 12, n. 5, p. 1185-1192, 2007. Disponível em:

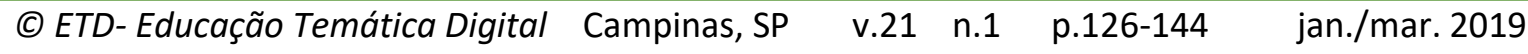


http://www.scielo.br/scielo.php?pid=S1413-81232007000500015\&script=sci arttext Acesso em: 18 jun. 2018.

REGUERA, Enrique Martínez. Crianças de ninguém, crianças de rua: psicologia da infância explorada. Porto Alegre: Artes Médicas, 2005.

SANABRIA, Ana Maria; RODRÍGUEZ, Ana Fernanda Uribe. Conductas antisociales y delictivas en adolescentes infractores y no infractores. Pensamiento Psicológico, Cali, v. 6, n. 13, p. 203-218, 2009. Disponível em:

http://revistas.javerianacali.edu.co/index.php/pensamientopsicologico/article/view/126. Acesso em: 20 jun. 2018.

SOUSA, Edson Luiz André de; GOLDMEIER, Paula. Juventude em tempos de violência.

Revista Mal-Estar e Subjetividade, Fortaleza, v. 8, n. 4, p. 991-1020, 2008. Disponível em: http://redalyc.uaemex.mx/src/inicio/ArtPdfRed.jsp?iCve=27111861007 Acesso em: 18 jun. 2018.

SPOSITO, Marilia Pontes (Coord.). Estado do conhecimento: juventude e escolarização. São Paulo: Ação Educativa/Inep, 2000.

THOMPSON, Paul. A voz do passado. Tradução de Lólio Lourenço de Oliveira. Rio de Janeiro: Paz e Terra, 1992.

VEYNE, Paul. Como se escreve a história: Foucault revoluciona a história. Tradução de Alda Baltar e Maria Auxiliadora Kneipp. 3. ed. Brasília, DF: UnB, 1995.

VOLPI, Mário. O adolescente e o ato infracional. Inalud, v. 14, p. 21-32, 2001.

WAISELFISZ, Julio Jacobo. Mapa da violência 2016: homicídios por armas de fogo no Brasil. Rio de Janeiro: Flacso/Cebela, 2016. Disponível em:

http://www.mapadaviolencia.org.br/pdf2016/Mapa2016 armas web.pdf. Acesso em: 9 set. 2016.

ZANELLA, Maria Nilvane; LARA, Angela Mara de Barros. A ONU, suas normativas e o ordenamento jurídico para o atendimento de adolescentes em conflito com a lei no Brasil: as políticas de socioeducação. Educação Temática Digital, Campinas, v. 17, n. 1, p. 176-192, 2015. Disponível em:

http://periodicos.sbu.unicamp.br/ojs/index.php/etd/article/view/8634825 . Acesso em: 20 dez. 2017.

Revisão gramatical do texto sob responsabilidade de:

Felipe Aragão de Freitas Carneiro.

E-mail: felipearagaofc@hotmail.com

(C) ETD-Educação Temática Digital Campinas, SP $\quad$ v.21 n.1 $\quad$ p.126-144 jan./mar. 2019 